\title{
Game Edukasi Pembelajaran Sejarah Berdirinya Indonesia Untuk Sekolah Dasar
}

\author{
Agam Arta, Devi Afriyantari Puspa Putri \\ Program Studi Informatika \\ Universitas Muhammadiyah Surakarta \\ Surakarta, Indonesia \\ aggam97@gmail.com,dapi29@ums.ac.id
}

\begin{abstract}
Abstraksi-Ilmu pengetahuan tentang sejarah telah diajarkan pada murid SD dalam pendidikan di Indonesia, dimana materi pembelajaran telah sesuai dengan kurikulum yang ada di Indonesia. Namun dalam proses pembelajaran saat ini masih mengikuti metode lama, yaitu menyampaikan dan menjelaskan isi yang ada di dalam buku serta menggunakan pendukung proyektor apabila guru ingin menjelaskan melalui PowerPoint yang telah dibuat. Berdasarkan masalah tersebut diabuatlah aplikasi pembelajaran berupa game edukasi berbasis Android untuk kelas $4 \mathrm{SD}$, agar para murid tidak merasa jenuh saat diajarkan oleh guru dan memiliki ketertarikan terhadap sejarah terutama sejarah Indonesia. Perancangan aplikasi ini menggunakan Unity 5.6 dan CorelDraw X8 sebagai editing grafis. Tahapan untuk pengujian game edukasi ini menggunakan metode blackbox dan kuisioner, yang ditujukan kepada murid dan guru sebagai responden. Hasil yang didapatkan dari pengujian game edukasi tersebut menunjukkan bahwa aplikasi yang dijalankan pada beberapa perangkat Android berjalan dengan baik sesuai dengan harapan. Pada pengujian kuisioner, hasil yang didapatkan dari data yang telah diisi oleh murid dan guru rata-rata adalah $88,72 \%$. Dapat disimpulkan bahwa banyak yang tertarik oleh game edukasi tersebut dan dapat menjadi media berupa aplikasi pembelajaran sejarah agar para murid menjadi semangat ketika diterangkan pelajaran oleh guru.
\end{abstract} Unity

Katakunci-Android; Sejarah; Indonesia; Game; Edukasi;

\section{Pendahuluan}

Perkembangan media teknologi di Indonesia saat ini semakin maju dan tidak dapat dihindarkan dalam kehidupan masyarakat, khususnya di bidang permainan yang didukung oleh perkembangan software [1]. Salah satu yang sedang berkembang saat ini adalah sistem operasi Android. Anak pada usia 3-6 tahun berada pada masa pertumbuhan dan perkembangan paling pesat baik fisik maupun mental [2]. Tingkat 4 di usia sekolah dasar (SD) kita sudah diperkenalkan dengan mata pelajaran sejarah Indonesia, berdasarkan kurikulum yang digunakan oleh sistem pendidikan di Indonesia[3].
Mengenalkan media interaktif yang menarik membuat anak-anak usia SD yang secara logika masih menyukai game membuat media tersebut sangat diminati [4].

Perkembangan teknologi saat ini seharusnya bisa dimanfaatkan dengan tepat karena dengan memanfaatkan teknologi dapat membantu dan memudahkan proses belajar. Salah satu teknologi yang terus berkembang dan dapat memberikan pembelajaran yang menyenangkan adalah melalui game [5].

Berdasarkan beberapa masalah di atas, dapat disimpulkan bahwa perlu adanya proses dalam menyampaikan materi belajar kepada siswa, contohnya seperti game edukasi dengan memberikan alur permainan berupa game 3D yang menarik. Tujuannya agar para murid tidak merasa bosan dengan materi yang disampaikan guru dan siswa dapat termotivasi dan memahami dengan mudah mata pelajaran yang mereka terima di kelas.

\section{Tinjauan Pustaka}

Aplikasi game saat ini sedang berkembang pesat di sistem operasi Android. Salah satu game yang dapat dikembangkan adalah "Game Edukasi Puzzle Pengenalan Tokoh Sejarah Berbasis Android Dengan Metode Linier" [6]. Sedangkan penelitian yang lainnya adalah "Aplikasi Interaktif Pengenalan Pahlawan Revolusi Indoneseia Berbasis Multimedia" [7], dengan penyampaian yang menarik dan mudah dipahami dapat meningkatkan semangat kepahlawanan setiap siswa serta dapat mengenalkan siswa terhadap sejarah pahlawan revolusi Indonesia.

Berdasarkan penelitian tersebut terdapat kesamaan, yaitu tujuan peneliti dan penulis terdahulu ingin menciptakan aplikasi pembelajaran berupa game yang menarik, supaya daya minat dan ingat belajar anak-anak terhadap pelajaran dari sekolah dapat meningkat. Namun dalam pembuatan aplikasi tersebut terdapat beberapa perbedaan dalam pembuatannya, ada yang menggunakan software Construct 2, Android Studio dan Unity. 


\section{METODE}

Metode pengembangan sistem yang digunakan untuk analisa dan perancangan aplikasi game edukasi pembelajaran berdirinya Indonesia adalah dengan menggunakan model sequential linear yang diperkenalkan oleh Winston Walker Royce pada tahun 1970, model tersebut juga dikenal sebagai metode waterfall. Adapun proses pengerjaannya dapat dilihat pada Gambar 1.

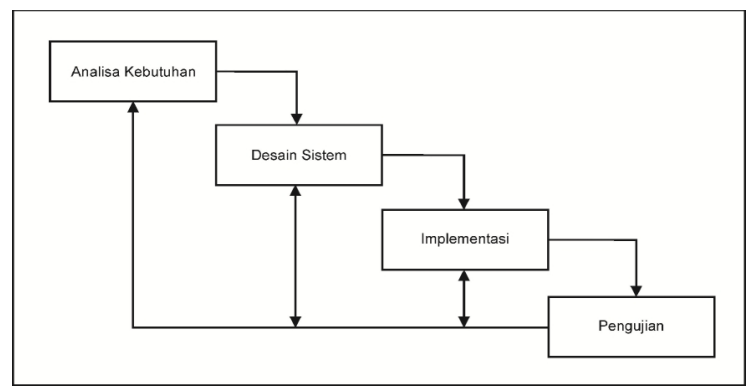

Gambar 1. Tahap metode waterfall

\section{A. Analisis Kebutuhan}

Pada tahap analisis kebutuhan ada beberapa proses yang perlu dilakukan. Pertama, pengumpulan data yang akan dibutuhkan. Data diperoleh melalui referensi dari buku tematik untuk kelas 4 dan wawancara terhadap guru yang mengajar. Kedua, identifikasi masalah yang akan dikerjakan. Ketiga, mempersiapkan kebutuhan yang diperlukan untuk pembuatan game. Kebutuhan yang diperlukan berupa software dan hardware, seperti pada Tabel 1.

TABEL I. ANALISIS KEBUTUHAN HARDWARE DAN SOFTWARE

\begin{tabular}{|c|c|c|}
\hline & Software & Hardware \\
\hline & $\begin{array}{l}\text { Unity } 5.6 \\
\text { CorelDRAW X8 }\end{array}$ & $\begin{array}{ll}\text { 1. } & \text { Laptop Acer Aspire E5- } \\
& 55 \mathrm{G}-11 \mathrm{Q} \\
\text { 2. } & \mathrm{Xiaomi}{ }^{\mathrm{TM}} \text { Redmi Note } 5\end{array}$ \\
\hline
\end{tabular}

\section{B. Desain Sistem}

Pada tahap desain sistem akan ada penyesuaian kebutuhan yang diperlukan oleh user agar dapat mengetahui fungsi yang ada pada game edukasi. Adapun untuk mempermudah proses pengembangan, maka dibuat use case diagram agar mempermudah pengimplementasian desain ke dalam software Unity 5.6, seperti yang terlihat pada Gambar 2.

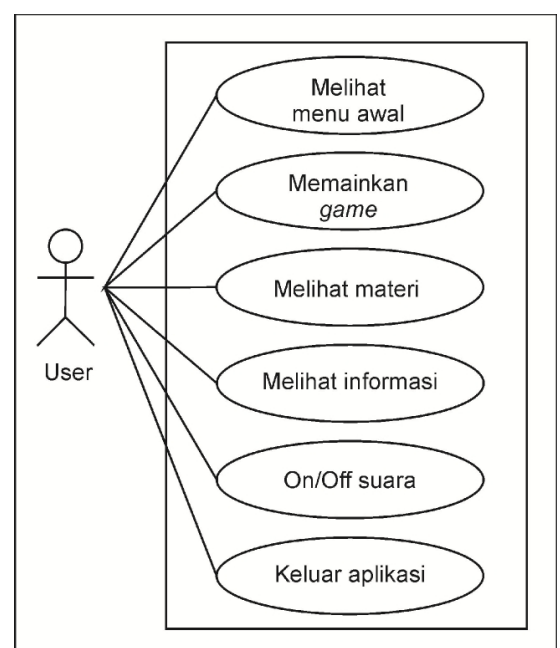

Gambar 2. Use case diagram

\section{Implementasi}

Tahap implementasi merupakan tahap penerapan hasil rancangan yang telah dibuat sebelumnya dan diterapkan ke dalam kode program. Dalam pengembangan game akan menggunakan software Unity 5.6 sebagai pemrograman game. Desain grafis akan menggunakan CorelDRAW X8 sebagai editing grafis untuk membuat objek gambar, agar tampilan dalam game sesuai dengan rancangan.

\section{Pengujian}

Ada dua pengujian pada aplikasi game ini, yaitu menggunakan metode pengujian blackbox dan kuisioner. Pengujian dengan metode blackbox digunakan untuk menguji komponen-komponen dari sebuah sistem, tujuannya agar mengetahui seluruh sistem yang dibuat dapat berfungsi sesuai yang diharapkan. Sedangkan pengujian menggunakan kuisioner bertujuan untuk mendapatkan tanggapan dari penggunanya mengenai game yang dijalankan. Menggunakan metode tersebut anak-anak yang tidak mengerti coding dapat menilai aplikasi yang mereka jalankan. Adapun kuisioner dapat dilihat pada Tabel 2.

TABEL II. KUISIONER PENGUJiAn APLIKASI

\begin{tabular}{|c|c|c|c|c|c|c|}
\hline \multirow{2}{*}{ No. } & \multirow{2}{*}{ Pertanyaan } & \multicolumn{5}{|c|}{ Pilihan Jawaban } \\
\hline & & SS & $\mathbf{S}$ & $\mathbf{N}$ & TS & STS \\
\hline 1. & Apakah aplikasi ini menarik? & & & & & \\
\hline 2. & $\begin{array}{l}\text { Apakah aplikasi ini mudah } \\
\text { untuk digunakan? }\end{array}$ & & & & & \\
\hline 3. & $\begin{array}{l}\text { Apakah bahasa yang digunakan } \\
\text { mudah dimengerti? }\end{array}$ & & & & & \\
\hline 4. & $\begin{array}{l}\text { Pertanyaan dalam aplikasi dapat } \\
\text { dikerjakan }\end{array}$ & & & & & \\
\hline 5. & $\begin{array}{l}\text { Materi pembelajaran mudah } \\
\text { dipahami }\end{array}$ & & & & & \\
\hline 6. & $\begin{array}{l}\text { Tampilan aplikasi tidak } \\
\text { membosankan }\end{array}$ & & & & & \\
\hline 7. & $\begin{array}{l}\text { Aplikasi dapat membantu } \\
\text { memahami materi pembelajaran }\end{array}$ & & & & & \\
\hline 8. & $\begin{array}{l}\text { Aplikasi dapat meningkatkan } \\
\text { minat belajar }\end{array}$ & & & & & \\
\hline 9. & $\begin{array}{l}\text { Tombol dalam aplikasi } \\
\text { berfungsi dengan baik }\end{array}$ & & & & & \\
\hline 10. & $\begin{array}{l}\text { Tombol dalam aplikasi dapat } \\
\text { digunakan dengan mudah dan } \\
\text { dimengerti }\end{array}$ & & & & & \\
\hline
\end{tabular}

\section{Hasil Dan PEMbahasan}

Setelah tahapan sebelumnya selesai maka pada penelitian ini menghasilkan sebuah aplikasi game edukasi (Pembelajaran Sejarah Berdirinya Indonesia Untuk Sekolah Dasar). Hasil dari perancangan aplikasi ini dapat dijelaskan sebagai berikut:

\section{A. Halaman Awal}

Tampilan awal game terlihat pada Gambar 3. Saat halaman awal muncul akan terdengar backsound pada awal game. Halaman awal ini memiliki tampilan beberapa menu utama, yaitu menu mulai, materi, tentang dan keluar serta menu pendukung seperti untuk mematikan atau menghidupkan backsound. 


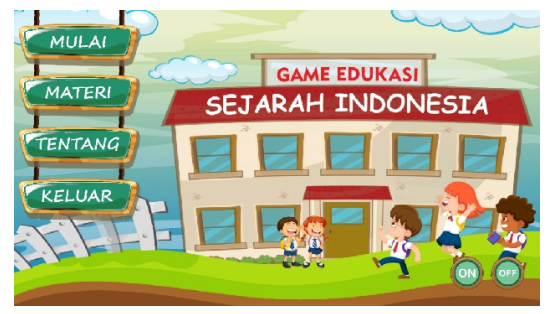

Gambar 3. Halaman awal game

\section{B. Menu Mulai}

Menu mulai akan ditampilkan seperti pada Gambar 4, terdapat beberapa pilihan level didalamnya serta tombol pendukung seperti tombol reset supaya dapat memulai dari level awal dan tombol petunjuk supaya mempermudah user dalam menyelesaikan game. Halaman petunjuk dapat dilihat pada Gambar 5.

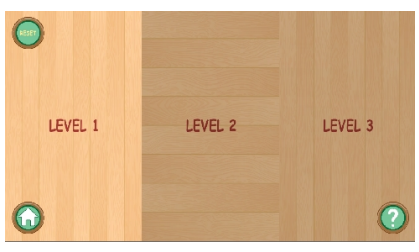

Gambar 4. Halaman menu mulai

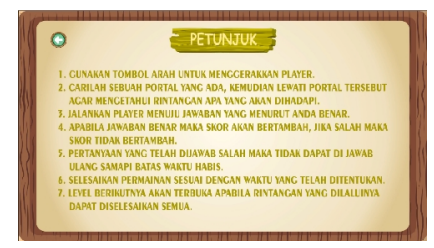

Gambar 5. Halaman petunjuk
Ketika user menekan tombol level yang dapat dimainkan, maka user diperintahkan untuk mencari beberapa portal dan menyelesaikan rintangan sesuai pada halaman petunjuk. Tampilan lebih jelasnya dapat dilihat pada Gambar 6 .

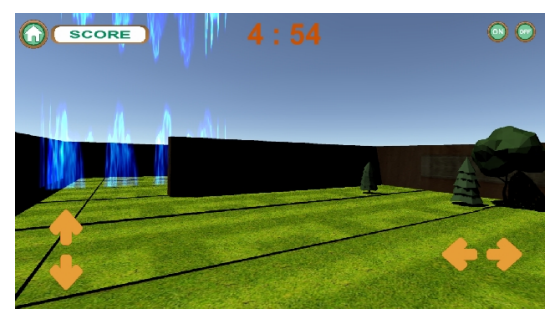

Gambar 6. Halaman game

User akan diarah ke halaman menang apabila dapat menyelesaikan geme tersebut, jika user tidak dapat menyelesaikan game yang dimainkan maka akan diarahkan ke halaman kalah. Tampilan lebih jelasnya dapat dilihat pada Gambar 7 dan 8.

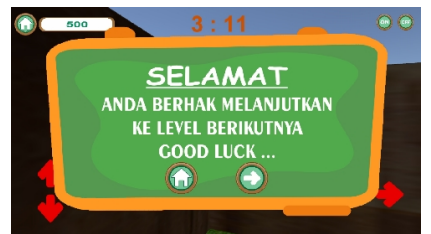

Gambar 7. Halaman menang

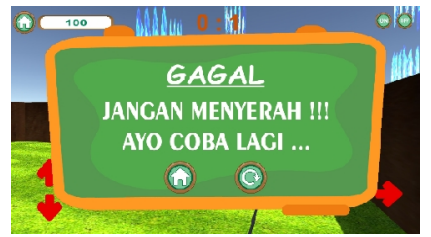

Gambar 8. Halaman kalah

\section{Menu Materi}

Tampilan halaman menu materi dapat dilihat pada Gambar 9 dan 10. Menu materi ini terdapat beberapa tombol pendukung, seperti tombol next untuk melihat halaman slide berikutnya, tombol back untuk melihat halaman slide sebelumnya dan tombol home untuk kembali ke menu utama. Pada halaman ini terdapat backsound sesuai dengan judul apabila user menekan gambar yang ada di setiap halaman slide tersebut.

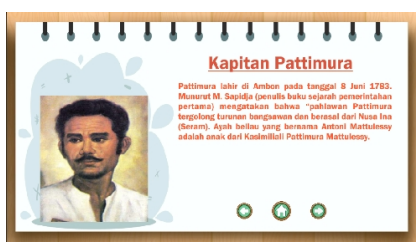

Gambar 9. Halaman menu materi

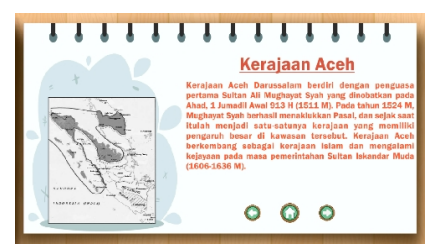

Gambar 10. Halaman menu materi

\section{Menu Tentang}

Tampilan halaman menu tentang dapat dilihat pada Gambar 11, 12, 13 dan 14. Halaman menu tentang berisi deskripsi singkat tentang pembuat, tujuan pembuatan game dan beberapa credit sebagai pendukung proses pembuatan game edukasi ini.

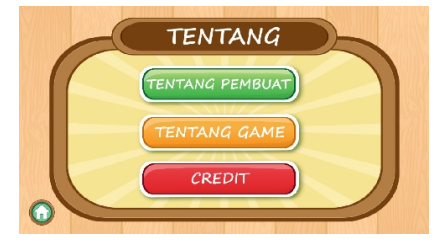

Gambar 11. Halaman menu tentang

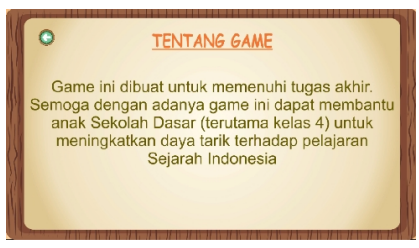

Gambar 13. Halaman menu tentang game
Gambar 12. Halaman menu tentang pembuat

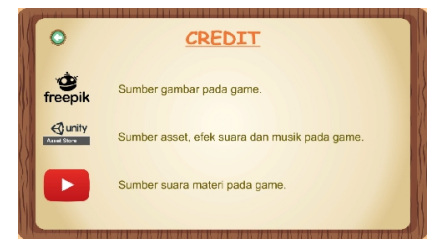

Gambar 14. Halaman menu credit

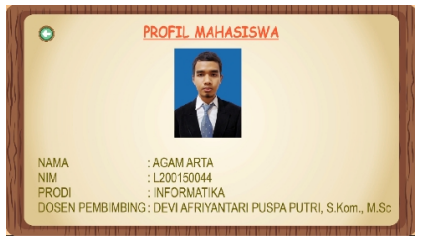

\section{Pengujian}

Pengujian dan penelitian game ini dilakukan di SDN 02 Gonilan. Pengujian tersebut ditujukan kepada siswa kelas 4 SD dan wali kelas dengan menggunakan metode pengujian blackbox dan kuisioner.

\section{A. Pengujian Blackbox}

Tahap ini digunakan untuk pengujian blackbox yang bertujuan untuk mengetahui apakah aplikasi dapat berjalan dan berfungsi dengan harapan sebelumnya. Hasil dari pengujian blackbox pada aplikasi ini terdapat pada Tabel 3. 
TABEL III. Hasil Pengujian BLACKBOX

\begin{tabular}{|c|c|c|c|c|}
\hline Bagian & Pengujian & $\begin{array}{c}\text { Bentuk } \\
\text { Pengujian }\end{array}$ & $\begin{array}{c}\text { Hasil Yang } \\
\text { Diharapkan }\end{array}$ & Hasil \\
\hline \multirow{5}{*}{$\begin{array}{l}\text { Menu } \\
\text { Utama }\end{array}$} & $\begin{array}{l}\text { Menu } \\
\text { Mulai }\end{array}$ & $\begin{array}{l}\text { Klik Tombol } \\
\text { Mulai }\end{array}$ & $\begin{array}{c}\text { Menampilkan Pilihan } \\
\text { Level }\end{array}$ & Valid \\
\hline & $\begin{array}{l}\text { Menu } \\
\text { Materi }\end{array}$ & $\begin{array}{c}\text { Klik Tombol } \\
\text { Materi }\end{array}$ & $\begin{array}{c}\text { Menampilkan Halaman } \\
\text { Menu Materi }\end{array}$ & Valid \\
\hline & $\begin{array}{c}\text { Menu } \\
\text { Tentang }\end{array}$ & $\begin{array}{l}\text { Klik Tombol } \\
\text { Tentang }\end{array}$ & $\begin{array}{c}\text { Menampilkan Halaman } \\
\text { Menu Tentang }\end{array}$ & Valid \\
\hline & $\begin{array}{l}\text { Tombol } \\
\text { On Atau } \\
\text { Off }\end{array}$ & $\begin{array}{l}\text { Klik Tombol } \\
\text { On Atau Off }\end{array}$ & $\begin{array}{l}\text { Menghidupkan Atau } \\
\text { Mematikan Suara }\end{array}$ & Valid \\
\hline & $\begin{array}{l}\text { Tombol } \\
\text { Keluar } \\
\end{array}$ & $\begin{array}{l}\text { Klik Tombol } \\
\text { Keluar }\end{array}$ & Keluar Dari Aplikasi & Valid \\
\hline \multirow{4}{*}{$\begin{array}{l}\text { Menu } \\
\text { Mulai }\end{array}$} & $\begin{array}{l}\text { Halaman } \\
\text { Permainan }\end{array}$ & $\begin{array}{l}\text { Klik Tombol } \\
\text { Level }(1 / 2 / 3)\end{array}$ & $\begin{array}{c}\text { Menampilkan } \\
\text { Permainan Sesuai } \\
\text { Dengan Level Yang } \\
\text { Terbuka } \\
\end{array}$ & Valid \\
\hline & $\begin{array}{c}\text { Tombol } \\
\text { Tanya } \\
\end{array}$ & $\begin{array}{l}\text { Klik Tombol } \\
\text { Controller }\end{array}$ & $\begin{array}{c}\text { Menampilkan Cara } \\
\text { Menyelesaikan Game }\end{array}$ & Valid \\
\hline & $\begin{array}{l}\text { Tombol } \\
\text { Home }\end{array}$ & $\begin{array}{l}\text { Klik Tombol } \\
\text { Home }\end{array}$ & $\begin{array}{c}\text { Kembali Ke Menu } \\
\text { Utama }\end{array}$ & Valid \\
\hline & $\begin{array}{c}\text { Tombol } \\
\text { Reset }\end{array}$ & $\begin{array}{l}\text { Klik Tombol } \\
\text { Reset }\end{array}$ & $\begin{array}{c}\text { Mengunci Level Yang } \\
\text { Telah Terbuka } \\
\text { (Kecuali Level 1) }\end{array}$ & Valid \\
\hline \multirow{2}{*}{$\begin{array}{l}\text { Halaman } \\
\text { Permainan }\end{array}$} & $\begin{array}{c}\text { Tombol } \\
\text { Controller }\end{array}$ & $\begin{array}{l}\text { Klik Tombol } \\
\text { Controller }\end{array}$ & $\begin{array}{l}\text { Karakter Game Akan } \\
\text { Berjalan Maju, Mundur } \\
\text { Dan Ke Samping }\end{array}$ & Valid \\
\hline & $\begin{array}{l}\text { Tombol } \\
\text { Home }\end{array}$ & $\begin{array}{l}\text { Klik Tombol } \\
\text { Home }\end{array}$ & Keluar Dari Permainan & Valid \\
\hline \multirow{3}{*}{$\begin{array}{l}\text { Halaman } \\
\text { Menang }\end{array}$} & $\begin{array}{c}\text { UI } \\
\text { Menang }\end{array}$ & $\begin{array}{c}\text { Menyelesaikan } \\
\text { Game }\end{array}$ & $\begin{array}{l}\text { Menampilkan Ucapan } \\
\text { Selamat Dan Semangat }\end{array}$ & Valid \\
\hline & $\begin{array}{l}\text { Tombol } \\
\text { Next }\end{array}$ & $\begin{array}{l}\text { Klik Tombol } \\
\text { Next }\end{array}$ & $\begin{array}{c}\text { Menampilkan Halaman } \\
\text { Pilihan Level Apabila } \\
\text { Ingin Melanjutkan Ke } \\
\text { Level Berikutnya }\end{array}$ & Valid \\
\hline & $\begin{array}{l}\text { Tombol } \\
\text { Home }\end{array}$ & $\begin{array}{l}\text { Klik Tombol } \\
\text { Home }\end{array}$ & $\begin{array}{c}\text { Kembali Ke Menu } \\
\text { Utama }\end{array}$ & Valid \\
\hline \multirow{3}{*}{$\begin{array}{l}\text { Halaman } \\
\text { Kalah }\end{array}$} & UI Kalah & $\begin{array}{l}\text { Menjalankan } \\
\text { Game Dan } \\
\text { Kehabisan } \\
\text { Waktu }\end{array}$ & $\begin{array}{l}\text { Menampilkan Ucapan } \\
\text { Gagal Dan Memberi } \\
\text { Semangat Agar Jangan } \\
\text { Menyerah }\end{array}$ & Valid \\
\hline & $\begin{array}{l}\text { Tombol } \\
\text { Retry }\end{array}$ & $\begin{array}{l}\text { Klik Tombol } \\
\text { Retry }\end{array}$ & $\begin{array}{c}\text { Menampilkan Game } \\
\text { Yang Sebelumnya } \\
\text { Dijalankan Yang Tidak } \\
\text { Menang }\end{array}$ & Valid \\
\hline & $\begin{array}{l}\text { Tombol } \\
\text { Home }\end{array}$ & $\begin{array}{l}\text { Klik Tombol } \\
\text { Home }\end{array}$ & $\begin{array}{c}\text { Kembali Ke Menu } \\
\text { Utama }\end{array}$ & Valid \\
\hline \multirow{3}{*}{$\begin{array}{l}\text { Menu } \\
\text { Materi }\end{array}$} & $\begin{array}{l}\text { Halaman } \\
\text { Materi }\end{array}$ & $\begin{array}{l}\text { Klik Tombol } \\
\text { Materi Pada } \\
\text { Menu Utama }\end{array}$ & $\begin{array}{c}\text { Menampilkan } \\
\text { Informasi Materi }\end{array}$ & Valid \\
\hline & $\begin{array}{l}\text { Tombol } \\
\text { Next Dan } \\
\text { Back } \\
\end{array}$ & $\begin{array}{l}\text { Klik Tombol } \\
\text { Next Dan } \\
\text { Back } \\
\end{array}$ & $\begin{array}{c}\text { Manampilkan } \\
\text { Informasi Berikutnya } \\
\text { Dan Sebelumnya }\end{array}$ & Valid \\
\hline & $\begin{array}{l}\text { Tombol } \\
\text { Home }\end{array}$ & $\begin{array}{l}\text { Klik Tombol } \\
\text { Home }\end{array}$ & $\begin{array}{c}\text { Kembali Ke Menu } \\
\text { Utama }\end{array}$ & Valid \\
\hline \multirow{4}{*}{$\begin{array}{l}\text { Menu } \\
\text { Tentang }\end{array}$} & $\begin{array}{l}\text { Tombol } \\
\text { Tentang } \\
\text { Pembuat }\end{array}$ & $\begin{array}{c}\text { Klik Tombol } \\
\text { Tentang } \\
\text { Pembuat } \\
\end{array}$ & $\begin{array}{l}\text { Menampilkan Nama } \\
\text { Pembuat Game }\end{array}$ & Valid \\
\hline & $\begin{array}{l}\text { Tombol } \\
\text { Tentang } \\
\text { Game }\end{array}$ & $\begin{array}{l}\text { Klik Tombol } \\
\text { Tentang Game }\end{array}$ & $\begin{array}{c}\text { Menampilkan } \\
\text { Deskripsi Tentang } \\
\text { Game } \\
\end{array}$ & Valid \\
\hline & $\begin{array}{l}\text { Tombol } \\
\text { Credit }\end{array}$ & $\begin{array}{l}\text { Klik Tombol } \\
\text { Credit }\end{array}$ & $\begin{array}{l}\text { Menampilkan Daftar } \\
\text { Credit }\end{array}$ & Valid \\
\hline & $\begin{array}{l}\text { Tombol } \\
\text { Home }\end{array}$ & $\begin{array}{l}\text { Klik Tombol } \\
\text { Home }\end{array}$ & $\begin{array}{c}\text { Kembali Ke Menu } \\
\text { Utama }\end{array}$ & Valid \\
\hline
\end{tabular}

Berdasarkan hasil pengujian blackbox pada Tabel 3, maka dapat disimpulkan bahwa semua fungsi tombol pada game tersebut berjalan dengan baik sesui dengan fungsinya. Setelah pengujian blackbox selesai, pengujian selanjutnya dilakukan pada perangkat android.
TABEL IV. Hasil PEngujian PERANGKat ANDRoID

\begin{tabular}{|c|c|c|}
\hline Nama Perangakat & Spesifikasi & Hasil \\
\hline $\begin{array}{l}\text { Xiaomi Redmi Note } \\
5\end{array}$ & $\begin{array}{c}\text { RAM 4GB, OS Android Pie, Resolusi } \\
\text { Layar } 1080 \times 2160 \text { Pixel }\end{array}$ & $\begin{array}{c}\text { Berjalan } \\
\text { Dengan Baik }\end{array}$ \\
\hline Oppo A83 & $\begin{array}{l}\text { RAM 2GB, OS Android Noughat, } \\
\text { Resolusi Layar } 720 \text { x } 1440 \text { Pixel }\end{array}$ & $\begin{array}{c}\text { Berjalan } \\
\text { Dengan Baik }\end{array}$ \\
\hline $\begin{array}{l}\text { Xiaomi Redmi Note } \\
4 \mathrm{x}\end{array}$ & $\begin{array}{c}\text { RAM 3GB, OS Android } \\
\text { Marshmallow, Resolusi Layar } 1080 \mathrm{x} \\
\text { 1920 Pixel }\end{array}$ & $\begin{array}{c}\text { Berjalan } \\
\text { Dengan Baik }\end{array}$ \\
\hline
\end{tabular}

Hasil pengujian pada perangkat android pada Tabel 4, dapat disimpulkan dari keseluruhan perangkat android yang diujikan dapat menjalankan dan mengoperasikan game edukasi ini dengan baik dan sesuai dengan yang diharapkan.

\section{B. Pengujian Kuisioner}

Penelitian ini diterapkan pada kelas 4 SDN 02 Gonilan dengan membagikan lembar kuisioner yang telah disiapkan. Sebelum pengisian kuisioner, penulis menjelaskan dan menjalankan game edukasi yang dibuat secara langsung di depan kelas, supaya calon pengguna dapat memahami cara kerja game edukasi yang dibuat. Jumlah responden pada game ini ada 24 murid dan 1 guru kelas 4 . Hasil pengolahan dari kuisioner dapat dilihat pada Tabel 5.

TABEL V. HASil PENGUJiAn KUISIONER

\begin{tabular}{|c|c|c|c|c|c|c|c|c|}
\hline \multirow{2}{*}{ No } & \multirow{2}{*}{$\begin{array}{l}\text { Perta- } \\
\text { nyaan }\end{array}$} & \multicolumn{5}{|c|}{ Jumlah Jawaban } & \multirow{2}{*}{$\begin{array}{l}\text { Total } \\
\text { Nilai }\end{array}$} & \multirow{2}{*}{ Presentase } \\
\hline & & SS & $\mathbf{S}$ & $\mathbf{N}$ & TS & STS & & \\
\hline 1. & P1 & 22 & 3 & & & & 122 & $97,6 \%$ \\
\hline 2. & $\mathrm{P} 2$ & 8 & 8 & 8 & & 1 & 97 & $77,6 \%$ \\
\hline 3. & P3 & 13 & 9 & 3 & & & 110 & $88 \%$ \\
\hline 4. & $\mathrm{P} 4$ & 10 & 12 & 1 & 2 & & 105 & $84 \%$ \\
\hline 5. & P5 & 10 & 12 & 3 & & & 107 & $85,6 \%$ \\
\hline 6. & P6 & 15 & 5 & 3 & 1 & 1 & 107 & $85,6 \%$ \\
\hline 7. & P7 & 17 & 6 & 2 & & & 115 & $92 \%$ \\
\hline 8. & P8 & 18 & 5 & 1 & & 1 & 114 & $91,2 \%$ \\
\hline 9. & P9 & 15 & 7 & 3 & & & 112 & $89,6 \%$ \\
\hline 10. & P10 & 15 & 9 & 1 & & & 120 & $96 \%$ \\
\hline \multicolumn{8}{|c|}{ Nilai Rata-Rata Presentase } & $88,72 \%$ \\
\hline
\end{tabular}

Skor ideal dari hasil pengujian kuisioner yang didapat menggunakan rumus persamaan 1 . Jadi skor ideal dalam kuisioner tersebut adalah $5 \times 25=125$.

$$
\begin{gathered}
\text { Skor ideal }=\sum 5 \times \text { Jumlah responden } \\
\text { Presentase }=\frac{\text { Nilai }}{\text { Skor ideal }} \times 100 \%
\end{gathered}
$$

Keterangan: 5 didapat dari nilai SS.

Presentase dari hasil penghitungan data pengujian kuisioner yang didapat, menghitungnya menggunakan rumus persamaan 2. Grafik diagram dari pengujian kuisioner di atas dapat dilihat pada Gambar 15. 


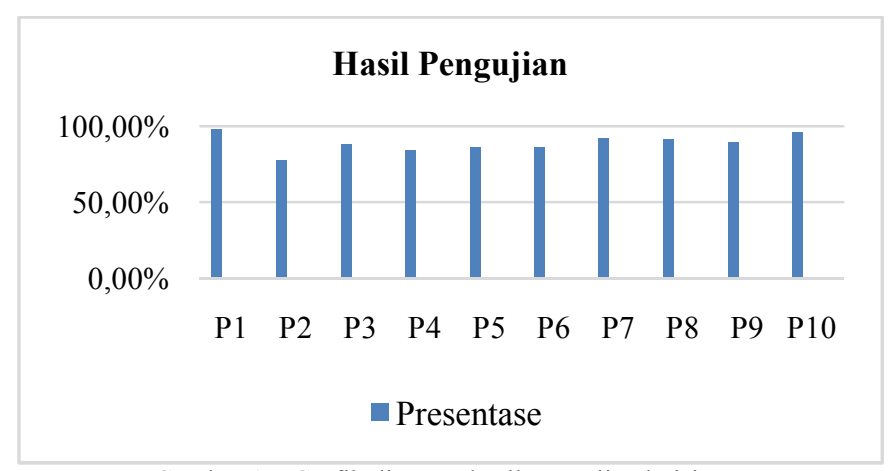

Gambar 15. Grafik diagram hasil pengujian kuisioner

\section{Penutup}

Berdasarkan dari hasil penelitian yang telah dilakukan, dapat ditarik kesimpulan sebagai berikut.

1. Aplikasi game edukasi ini memiliki dua menu utama, yaitu menu mulai dan materi. Pada menu mulai user pada awal permainan hanya dapat memainkan pada level 1, level berikutnya akan dapat dimainkan apabila level sebelumnya telah diselesaikan dengan benar sesuai dengan waktu yang disediakan. Adapun menu materi, didalamnya terdapat materi pembelajaran yang berkaitan dengan menu mulai, sehingga user harus mempelajari isi dari menu materi dahulu agar lancar dalam menyelesaikan game tersebut.

2. Berdasarkan pengujian terhadap beberapa perangkat android, aplikasi ini dapat berjalan dengan baik dan tanpa terbebani oleh sesuatu yang tidak diinginkan.

3. Nilai rata-rata presentase penerimaan terhadap pengguna adalah $88,72 \%$, hal itu menunjukkan bahwa aplikasi ini dapat menarik perhatian murid SD terutama kelas 4 , serta dapat membantu meningkatkan minat belajar murid SD dalam mempelajari pelajaran sejarah Indonesia.

\section{DAFTAR PUSTAKA}

[1] T. F. Prasetyo, H. Sanjaya, and D. Santana, "Aplikasi Game Edukatif Tebak Nama Pahlawan Nasional (GNPI) Berbasis Multimedia Interaktif", pp. 28-32, 2016.

[2] D. L. Fithri and D. A. Setiawan, "Analisa Dan Perancangan Game Edukasi Sebagai Motivasi Belajar Untuk Anak Usia Dini", vol. 8, no. 1, pp. 225-230, 2017.

[3] Afriki, dkk, "Tema 7 INDAHNYAKERAGAMAN DINEGERIKU Buku Tematik Terpadu Kurikulum 2013 Buku Guru SD/MI Kelas IV", Kementrian Pendidikan dan Kebudayaan, Jakarta, 2013.

[4] P. L. Ekawati and A. Z. Falani, "Pemanfaatan Teknologi Game Untuk Pembelajaran Mengenal Ragam Budaya Indonesia Berbasis Android", vol. 22, no. 1, pp. 30-36, 2015.

[5] D. Irsa, R. Wiryasaputra, and S. Primasari, "Perancangan Game Edukasi Pembelajaran Anak Usia Dini Menggunakan Linear Congruent Method (LCM) Berbasis Android", vol. 6, no. 1, pp 7-14, 2015.

[6] Jeffry and J. Petrus, "Rancang Bangun Aplikasi Game Edukasi Puzzle Pengenalan Tokoh Sejarah Berbasis Android Dengan Metode Linear Congruential Generator (LCG), 2014.

[7] B. Agus, Triono, and A. Desy, "Aplikasi Interaktif Pengenalan Pahlawan Revolusi Indonesia Berbasis Multimedia", Jurnal Sisfotek Global, vol. 4, no. 2, pp. 36-40. 